\title{
The Proposed PASI-HD Provides More Precise Assessment of Plaque Psoriasis Severity in Anatomical Regions with a Low Area Score
}

\author{
Kim A. Papp · Mark G. Lebwohl - Leon H. Kircik · David M. Pariser • \\ Bruce Strober · Gerald G. Krueger · David R. Berk · Lynn Navale • \\ Robert C. Higham
}

Received: May 10, 2021 / Published online: July 8, 2021

(C) The Author(s) 2021

\section{ABSTRACT}

The Psoriasis Area and Severity Index (PASI) is the most widely used clinical measure in clinical trials to assess disease severity of plaque psoriasis. However, the PASI is not a precise measure of severity with less precision when the regional area of involvement is $<10 \%$ of the BSA of a specific anatomical region. Degradation of precision results from the area score defaulting to ' 1 ' when the area of involvement within an anatomical region falls between $0 \%$ and $10 \%$ of the BSA for a given anatomical region. We describe a modification to the PASI, termed PASI-high discrimination (PASI-HD), for

K. A. Papp

Probity Medical Research and K. Papp Clinical

Research, Waterloo, ON, Canada

M. G. Lebwohl · L. H. Kircik

Icahn School of Medicine at Mount Sinai, New York, NY, USA

L. H. Kircik

Indiana Medical Center, Indianapolis, IN, USA

L. H. Kircik

Physicians Skin Care, PLLC and Skin Sciences, Louisville, KY, USA

D. M. Pariser

Department of Dermatology, Eastern Virginia

Medical School and Virginia Clinical Research, Inc.,

Norfolk, VA, USA determination of more accurate psoriasis severity in body regions where $<10 \%$ of the body surface area is affected. The methodology for assessing disease severity in these conditions is described.

Keywords: Low body surface area; Methodology; PASI; PASI-HD; Plaque psoriasis; Severity

B. Strober

Yale University School of Medicine, New Haven, CT, USA

B. Strober

Central Connecticut Dermatology, Cromwell, CT, USA

G. G. Krueger

University of Utah, School of Medicine, Salt Lake

City, UT, USA

D. R. Berk · L. Navale · R. C. Higham ( $₫)$

Arcutis Biotherapeutics, Inc., 3027 Townsgate Road, Suite 300, Westlake Village, CA 91361, USA e-mail: rhigham@arcutis.com 


\section{Key Summary Points}

Disease severity is an important outcome measure in clinical trials of treatments for plaque psoriasis.

The most widely used clinical measure to assess disease severity of plaque psoriasis is the Psoriasis Area and Severity Index (PASI).

In determining the PASI score, area of involvement of the body region is estimated and given a number; however, for areas $<10 \%$ a non-granular score of 1 is applied regardless of the actual extent of affected area.

To address this limitation of the PASI for affected areas $<10 \%$, we describe the methodology for the PASI-high discrimination (PASI-HD), a modification to the PASI.

\section{COMMENTARY}

Psoriasis Area and Severity Index (PASI) is the standard measure to assess severity of plaque psoriasis in clinical trials [1]. A limitation of PASI is that it is less accurate when the affected body surface area (BSA) is $<10 \%$. Topical treatments are the most commonly used for patients with mild to moderate psoriasis (involving $<10 \% \mathrm{BSA}$ ) or to treat disease flaring from and within areas with $<10 \%$ involvement [2]. With innovations in topical treatments for psoriasis, a more precise estimate of PASI is necessary to evaluate these results. The aim of this commentary is to introduce the PASI-high discrimination (PASI-HD), a measure designed to be used in clinical trials to provide greater precision in estimating disease severity and evaluate treatment effectiveness. PASI-HD remains true to the PASI measure by maintaining the anatomical regions of the PASI. PASI-HD provides a higher level of discrimination and a more accurate evaluation of treatment effectiveness in patients in whom the areas of affected body surface within the anatomical regions measured by PASI are $<10 \%$. The method used to calculate PASI-HD follows.

PASI is determined by assessing severity in four anatomical regions (head/neck, upper extremities, trunk, and lower extremities) [1]. Each of the three primary clinical signs of psoriasis-erythema, induration, and desquamation-is ranked as an average severity across each region using a scale of 0 (none) to 4 (maximum) and added together generating an overall severity score for each body region. Next, the area of involvement in the body region is determined and assigned area scores based upon the proportion of the anatomical region involved with psoriasis. Area scores are multiplied by severity scores for a region-proportionate score. In body regions where the area of psoriasis is $<10 \%$, using the traditional PASI, an area score of 1 is given. This is the point of differentiation of PASI-HD versus PASI. Our modification for PASI-HD generates a linear score when the area of involvement is $<10 \%$ of the anatomical region; scores of $1-9 \%$ become 0.1-0.9 (in place of 1 with PASI). The affected area can be estimated using the size of the patient's hand as a relative standard. One palmar surface of the hand and fingers is approximately $1 \%$ of total BSA. Smaller area of psoriasis can be estimated using the thumb (0.1\%), thumb nail $(0.02 \%)$, and fifth-finger nail $(0.01 \%)$, as shown in Fig. 1 . The measures were developed consistently with the origination of the PASI measure, which determined that the area from the proximal crease of the palm/wrist to the tips of the fingers is roughly $1 \%$ of the BSA. To create the higher level of discrimination used in the PASI-HD, the $0.1 \%$ area of the thumb was determined by approximating that ten thumb units (from the base of the thumb to the tip of the thumb) fit across the palmar surface $(1 \%)$. Similarly, five thumbnails fit within each thumb unit $(0.1 \%)$, resulting in an area measure of $0.02 \%$. Finally, the fifth fingernail fits within the thumbnail $(0.02 \%)$ approximately two times, resulting in an area measure of $0.01 \%$. 


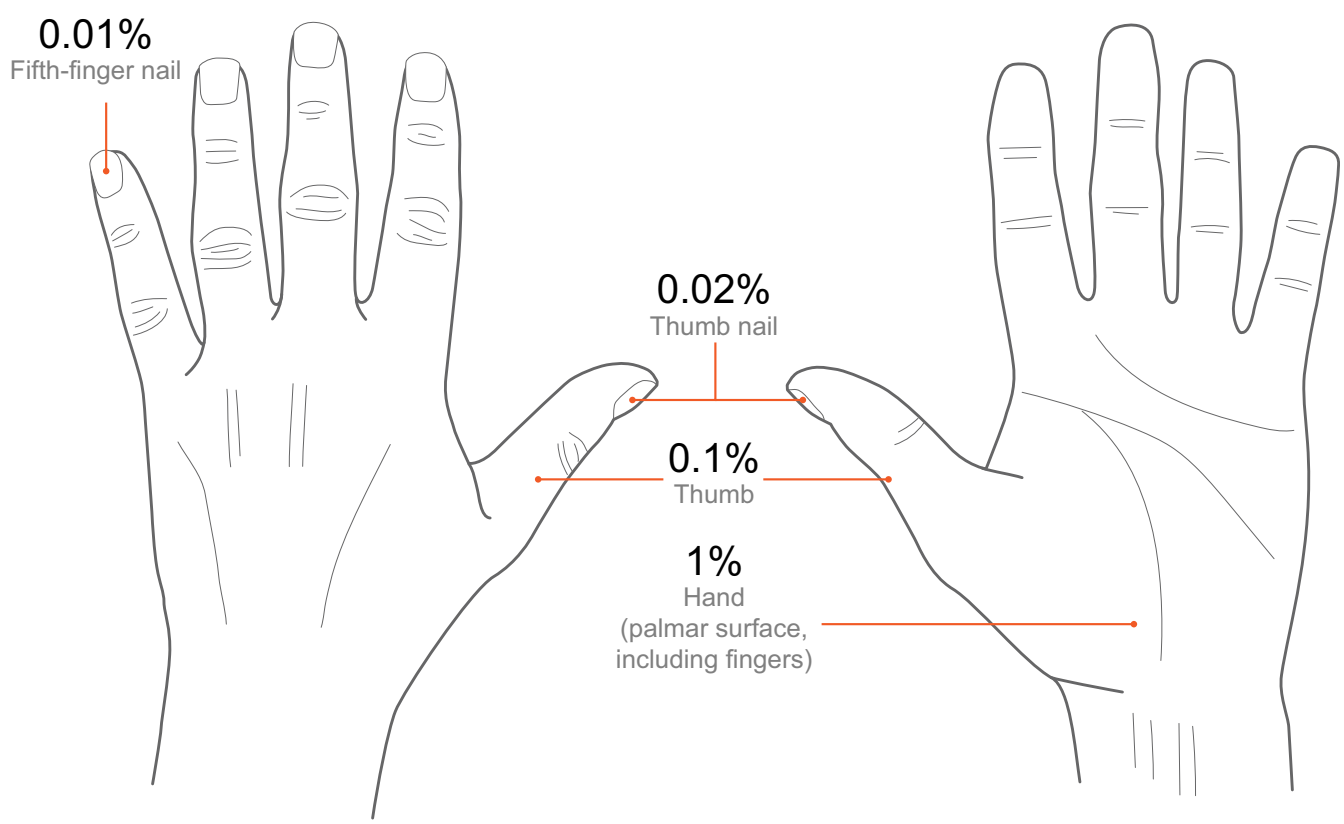

Fig. 1 Depiction of locations on the hand to use in estimating the area of psoriasis involvement when $<10 \%$

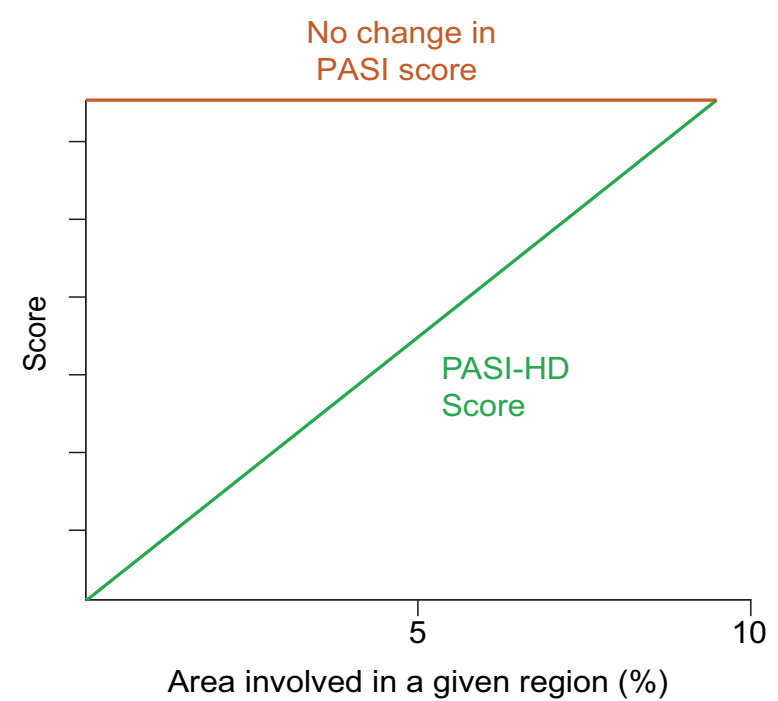

Fig. 2 Illustration of the relationship between PASI-HD and PASI. The severity scores are the same for PASI-HD and PASI when the affected area is $\geq 10 \%$. Below $10 \%$, more precise determination of a severity score can be obtained with PASI-HD, but the PASI remains static when the area of involvement declines further

Representation of the relationship between PASI-HD and PASI is illustrated in Fig. 2. The scoring method is identical for areas of psoriasis with $\geq 10 \%$ involvement. However, if the area involved falls below $10 \%$ with treatment, a reduction in the severity score to reflect clinical improvement can be obtained only with the PASI-HD. Similarly, PASI-HD more precisely captures disease flaring from and within areas with $<10 \%$ involvement (e.g., after treatment withdrawal).

Other alternatives to the PASI have been suggested by researchers. Physician Global Assessment (PGA) is an outcome measure to assess severity, but provides an average score of disease severity across anatomical regions [3]. The previously described PGAxBSA [4] is similar to PASI-HD in that both are discriminating and linear from $100 \%$ to $0 \%$; however, PASI-HD preserves the anatomical component of the PASI measure by assessing the severity and percentage area affected score in the four body regions. Preserving the anatomical regions and body surface area weighting, the areas can be individually assessed allowing a more precise score.

We propose that the PASI-HD provides higher discrimination of effects of treatment in areas with $<10 \%$ involvement than the 
traditional PASI while maintaining the anatomical component of the PASI. Because most patients with psoriasis have mild to moderate disease, this higher level of discrimination with the PASI-HD allows for a more accurate evaluation of treatment effectiveness as a function of BSA in these patients.

\section{ACKNOWLEDGEMENTS}

Funding. No funding or sponsorship was received for publication of this article.

Medical Writing and Editorial Assistance. Medical writing support was provided by Susan Sutch, PharmD, of Alligent Biopharm Consulting LLC, funded by Arcutis Biotherapeutics.

Authorship. All named authors meet the International Committee of Medical Journal Editors (ICMJE) criteria for authorship for this article, take responsibility for the integrity of the work as a whole, and have given their approval for this version to be published.

Authors' Contributions. All authors contributed to the manuscript conception and design. All authors commented on previous versions of the manuscript. All authors read and approved the final manuscript.

Disclosures. Kim A. Papp: is an investigator, consultant, speaker, scientific officer or has served on steering committees or advisory boards for AbbVie, Akros, Amgen, Anacor, Arcutis, Astellas, Bausch Health/Valeant, Baxalta, Boehringer Ingelheim, Bristol Myers Squibb, Can-Fite Biopharma, Celgene, Coherus, Dermira, Dow Pharmaceuticals Sciences, Inc., Eli Lilly, Evelo, Galderma, Galpagos, Genentech, Gilead, GSK, Janssen, Kyowa Hakko Kirin, Leo, Medimmune, Meiji Seika Pharma, Merck (MSD), Merck-Serono, Mitsubishi Pharma, Moberg Pharma, Novartis, Pfizer, PRCL Research, Regeneron, Roche, Sanofi-Aventis/ Genzyme, Sun Pharma, Takeda, and UCB Pharma. Mark G. Lebwohl: reports receipt of research funds from AbbVie, Amgen, Arcutis, Boehringer Ingelheim, Dermavant, Eli Lilly, Incyte, Janssen Research \& Development, LLC, LEO Pharma, Ortho Dermatologics, Pfizer, and UCB Pharma and serves as a consultant for Aditum Bio, Allergan, Almirall, Arcutis, Inc., Avotres Therapeutics, BirchBioMed Inc., BMD skincare, Boehringer Ingelheim, Bristol Myers Squibb, Cara Therapeutics, Castle Biosciences, Corrona, Dermavant, Evelo, Facilitate International Dermatologic Education, Foundation for Research and Education in Dermatology, Inozyme Pharma, LEO Pharma, Meiji Seika Pharma, Menlo, Mitsubishi, Neuroderm, Pfizer, Promius/ Dr. Reddy's Laboratories, Serono, Theravance, and Verrica. Leon H. Kircik: is an investigator, consultant, speaker, and/or advisory board member for Abbott Laboratories, Acambis, Aclaris, Allergan, Inc., Almirall, Amgen Inc., Anacor Pharmaceuticals, Assos Pharma, Astellas Pharma US, Inc., Asubio, Berlex Laboratories (Bayer HealthCare Pharmaceuticals), Biogen Idec, Biolife, Biopelle, Boehringer Ingelheim, Breckinridge Pharma, Colbar, Celgene, Centocor, Inc., Cellceutix, Cipher, Coherus, CollaGenex, Combinatrix, Connetics Corporation, Coria, Dermavant, Dermira, Dermik Laboratories, Dow Pharmaceutical Sciences, Inc., Dusa, Eli Lilly, Embil Pharmaceuticals, EOS, Exeltis, Ferndale Laboratories, Inc., Foamix, Genentech, Inc., GlaxoSmithKline, PLC, Health Point, LTD, Idera, Intendis, Innocutis, Innovail, Isdin, Johnson \& Johnson, Laboratory Skin Care Inc., LEO Pharma, L'Oreal, 3M, Maruho, Medical International Technologies, Merck, Medicis Pharmaceutical Corp., Merz, Nano Bio, Novartis AG, Noven Pharmaceuticals, Nucryst Pharmaceuticals Corp., Obagi, Onset, OrthoNeutrogena, Promius, PediaPharma, QLT, Inc., PharmaDerm, Pfizer, PuraCap, Quinnova, Quatrix, Serono (Merck Serono International SA), SkinMedica, Inc., Stiefel Laboratories, Inc., Sun Pharma, Taro, TolerRx, Triax, UCB Pharma, Valeant Pharmaceuticals Intl, Warner-Chilcott, XenoPort, and ZAGE. David M. Pariser: is an investigator, consultant, and/or advisory board member for Abbott Laboratories, Almirall, Amgen, AOBiome, LLC, Asana Biosciences, LLC, Atacama Therapeutics, Bickel Biotechnology, Biofrontera AG, Bristol Myers Squibb, Celgene, 
Dermavant, Dermira, Eli Lilly and Company, LEO Pharma, US, Menlo Therapeutics, Merck \& Co., Inc, Novartis Pharmaceuticals Corp., Novo Nordisk A/S, Ortho Dermatologics, Pfizer, Regeneron, Sanofi, Stiefel, a GSK company, TDM SurgiTech, Inc., TheraVida, and Valeant Pharmaceuticals International. Bruce Strober: is a consultant (honoraria) for AbbVie, Almirall, Amgen, Arcutis, Arena, Aristea, Boehringer Ingelheim, Immunic Therapeutics, Bristol Myers Squibb, Connect Biopharma, Dermavant, Dermira, Equillium, Janssen, LEO Pharma, Eli Lilly, Meiji Seika Pharma, Mindera, Novartis, Pfizer, GlaxoSmithKline, UCB Pharma, Sun Pharma, Ortho Dermatologics, Regeneron, and Sanofi-Genzyme, and a speaker for AbbVie, Amgen, Eli Lilly, Janssen, and Sanofi-Genzyme. $\mathrm{He}$ is also a Co-scientific Director (consulting fee) for Corrona Psoriasis Registry and an investigator for Dermavant, AbbVie, Corrona Psoriasis Registry, Dermira, Cara Therapeutics, Novartis. He is Editor-in-Chief (honorarium) for Journal of Psoriasis and Psoriatic Arthritis. Gerald G. Krueger: is a consultant or advisory board member for Abbott, Amgen, Janssen Biotech, Eli Lilly, Novartis, Pfizer, Johnson \& Johnson (PSOLAR), Sun Pharma, and DermTech International. He has received lecture fees from Abbott, Amgen, Janssen Biotech, Novartis, and Eli Lilly. David R. Berk: Employee of Arcutis Biotherapeutics, Inc. Lynn Navale: was an employee of Arcutis Biotherapeutics, Inc. at the time this manuscript was written and approved for submission. Robert C. Higham: Employee and stockholder of Arcutis Biotherapeutics, Inc.

Compliance with Ethics Guidelines. This article is based on previously conducted studies and author clinical experience and does not contain any studies with human participants or animals performed by any of the authors.

Data Availability. Data sharing is not applicable to this article as no datasets were generated or analyzed during the current study.
Open Access. This article is licensed under a Creative Commons Attribution-NonCommercial 4.0 International License, which permits any non-commercial use, sharing, adaptation, distribution and reproduction in any medium or format, as long as you give appropriate credit to the original author(s) and the source, provide a link to the Creative Commons licence, and indicate if changes were made. The images or other third party material in this article are included in the article's Creative Commons licence, unless indicated otherwise in a credit line to the material. If material is not included in the article's Creative Commons licence and your intended use is not permitted by statutory regulation or exceeds the permitted use, you will need to obtain permission directly from the copyright holder. To view a copy of this licence, visit http://creativecommons.org/licenses/by$\mathrm{nc} / 4.0 /$.

\section{REFERENCES}

1. Fredriksson T, Pettersson U. Severe psoriasis-oral therapy with a new retinoid. Dermatologica. 1978;157(4):238-44.

2. Elmets CA, Korman NJ, Prater EF, et al. Joint AAD-NPF Guidelines of care for the management and treatment of psoriasis with topical therapy and alternative medicine modalities for psoriasis severity measures. J Am Acad Dermatol. 2021;84(2):432-70.

3. Langley RG, Feldman SR, Nyirady J, van de Kerkhof P, Papavassilis C. The 5-point Investigator's Global Assessment (IGA) Scale: a modified tool for evaluating plaque psoriasis severity in clinical trials. J Dermatolog Treat. $2015 ; 26(1): 23-31$.

4. Walsh JA, McFadden M, Woodcock J, et al. Product of the Physician Global Assessment and body surface area: a simple static measure of psoriasis severity in a longitudinal cohort. J Am Acad Dermatol. 2013;69(6): 931-7. 